\section{DISCUSSION}

The results offer clear support for the hypothesis that exposure to high ambient temperatures markedly reduces Ss' overall affective state. However, contrary to original predictions, the subsequent effects of heat on interpersonal attraction were less clear-cut than those observed in previous research (e.g., Griffitt, 1970; Griffitt \& Veitch, 1971). One possible explanation for this discrepancy involves procedural differences between the present and earlier studies. In the Griffitt experiments, the stimulus person was not present in the experimental rooms, and the only exposure of Ss to this person was through the bogus attitude survey. In the present experiemnt, however, Ss actually shared the laboratory experience with the stimulus person. In the hot condition, this situation may have served as an instance of "shared suffering," a type of experience which has been found to increase interpersonal attraction (e.g., Latané, Eckman, \& Joy, 1966). The finding that exposure to heat did not decrease the likability of the stimulus person but did tend to decrease desire to work in an experiment with this person lends further support to this "shared suffering" explanation. Additional research in which degree of direct interaction between the $S$ and confederate is systematically varied would be helpful in further testing this explanation.

Other procedural differences between the present study and those conducted by Griffitt may also account for the discrepancy in the influence of heat on attraction. For example, the Griffitt studies employed high ambient temperatures approximately $10^{\circ} \mathrm{F}$ higher than those used in the current experiment. Although the experimental rooms in the present study were judged by $S$ s to be quite uncomfortable and unpleasant in the hot condition, even higher temperatures may be necessary to demonstrate any consistent effects on attraction.
Still another explanation for the failure of the present experiment to demonstrate a clear relationship between ambeint temperature and attraction is that the personal evaluation manipulation may have been so strong (accounting for $53 \%$ of the variance) as to render any effect of temperature on attraction relatively undetectable. Additional research employing a wider range of temperatures and a larger number of levels of personal evaluations and attitude similarity may provide additional evidence concerning the validity of these explanations.

\section{REFERENCES}

Baron, R. A. Aggression as a function of ambient temperature and prior anger arousal. Journal of Personality \& Social Psychology, 1972, 21, 183-189.

Baron, R. A., \& Bell, P. A. Aggression and heat: Mediating effects of prior provocation and exposure to an aggressive model. Journal of Personality \& Social psychology, in press. Baron, R. A., \& Lawton, S. F. Environmental influences on aggression: The facilitation of modeling effects by high ambient temperatures. Psychonomic Science, 1972, 26, 80-83.

Byrne, D. The attraction paradigm. New York: Academic Press, 1971.

Byrne, D., \& Rhamey, R. Magnitude of positive and negative reinforcements as a determinant of attraction. Journal of Personality \& Social Psychology, 1965, 2, 884-889.

Griffitt, W. Environmental effects on interpersonal affective behavior: Ambient effective temperature and attraction. Journal of Personality \& Social Psychology, 1970, 15, 240-244.

Griffitt, W., \& Veitch, R. Hot and crowded: Influence of population density and temperature on interpersonal affective behavior. Journal of Personality \& Social Psychology, 1971, $17,92-98$.

Latané B., Eckman, J., \& Joy, V. Shared stress and interpersonal attraction. Journal of Experimental Social Psychology Supplement, 1966, 1, 80-94.

(Received for publication August 2, 1974.)

\title{
Relative weighting of positive and negative information and confidence in reports of behavioral intentions*
}

\author{
EMIL J. POSAVAC* \\ Loyola University of Chicago, Chicago, Illinois 60626
}

\begin{abstract}
Trait descriptions that varied in polarity from a neutral description were formed in order to compare the relative weights of positive and negative traits on reports of behavioral intentions (BIs). Forty-four Ss made marital BI judgments, and 82 Ss reported employ BIs. Negative traits were weighted more heavily than positive traits. Confidence in BI reports increased as the descriptions increased in polarity; but negative information did not consistently evoke more confidence than positive information. Hypotheses suggesting different patterns of responses to marital and employ BIs were not supported.
\end{abstract}

Hamilton and Huffman (1971) showed that negative information is weighted more heavily than positive

*Sponsored by E. B. Zechmeister, who takes full editorial responsibility for it.

Jack McKillip, Paul Lavrakas, and Susan Green are thanked for help at various stages of this experiment. Reprints may be obtained from the author at the Department of Psychology, 6525 North Sheridan R oad, Chicago, Illinois 6026. information in a person perception task using trait descriptions as stimuli. They also showed that the information integration principles (e.g., Anderson, 1967) developed using evaluative judgments can be applied to judgments of activity and potency. Posavac and McKillip (1972) extended this line of inquiry to reports of behavioral intentions (Triandis, 1965) and to confidence 
Table 1

Mean Behavioral Intention Ratings of the Trait Combinations

\begin{tabular}{|c|c|c|c|c|c|}
\hline \multirow{3}{*}{$\begin{array}{l}\text { Behavioral } \\
\text { Intention } \\
\text { Dimension }\end{array}$} & \multicolumn{5}{|c|}{ Stimulus Combination } \\
\hline & \multicolumn{2}{|c|}{ Favorable } & \multirow[t]{2}{*}{ Neutral } & \multicolumn{2}{|c|}{ Unfavorable } \\
\hline & HP & LP & & LP & HP \\
\hline Émploy & 15.70 & 14.35 & 10.78 & 6.23 & 3.07 \\
\hline Marry & 13.86 & 12.77 & 10.82 & 2.52 & 3.48 \\
\hline
\end{tabular}

Note-HP $=$ high polarization, $L P=$ low polarization

in the judgments of behavioral intentions (BIs). It was found that the set size effect in person perception (Anderson, 1967) did generalize to judgments of BIs and that confidence increased as the polarity of the stimuli judged became more extreme.

Posavac and McKillip (1972), following Anderson (1967), selected four subsets of traits for both BIs used. These subsets represent the most favorable traits (labeled "H"), moderately favorable traits $(\mathrm{M}+)$, moderately unfavorable traits (M-), and unfavorable traits (L). In constructing their stimuli, Posavac and McKillip (1972) varied the polarity of the traits and the number of traits forming a description. However, they did not use descriptions made up from more than one subset of traits as Hamilton and Huffman (1971) did. The present paper examines the relative weights of positive and negative information on reports of BIs and judgments of confidence when stimuli of different polarities are used in the same descriptions.

The major hypothesis tested was that BIs would follow the same pattern as the semantic differential judgments in that negative stimuli would be weighted more heavily than positive stimuli when heterogeneous descriptions are used. In addition, it was hypothesized that negative traits would be weighted more heavily for marry BIs than for employ BIs. This pattern was expected because a marital relationship is more permanent and intensive than an employer-employee relationship and because the data reported by Posavac and McKillip (1972) seemed to suggest such a relationship. The third hypothesis was that confidence would be higher the more extreme the mean favorability of the description departed from neutral. Lastly, if the major hypothesis was supported, then it was expected that negative heterogeneous descriptions would be judged more confidently than positive descriptions. Kanouse and Hanson (1972) marshall a considerable amount of evidence supporting the contention that negative information is considerably more important than positive information in evaluating others. If Ss are more willing to report extreme BIs toward negative stimuli, then it seems reasonable that they would be more confident of their reports.

\section{METHOD}

The traits used in this study are the same as those used by
Hamilton and Huffman (1971) and by Posavac and McKillip (1972). The traits were individually scaled in terms of the Ss' willingness to marry or to employ a person possessing the trait. On the basis of this prescaling, subsets of traits were chosen such that the mean of the ratings of the most favorable $(\mathrm{H})$ trait was as polarized from the scale midpoint as the mean of the most unfavorable $(\mathrm{L})$ traits and the mean of the moderately favorable traits $(M+)$ was as polarized from neutral as the mean of the moderately unfavorable traits $(\mathrm{M}-)$. There were two equivalent sets of traits for both employ and marry BIs. Posavac and McKillip (1972) include further details of the prescaling and the selection of the traits making up the subsets.

From these subsets of traits, descriptions of individuals were constructed in a way that the relative weightings of $\mathrm{H}$ vs $\mathrm{L}$ traits and $M+v s ~ M$ traits could be examined. It should be noted that the mean of the four traits making up a heterogeneous stimulus was as polarized from the scale midpoint as the stimulus to which it was compared.

Ss read the descriptions one at a time and indicated on 21-point scales whether they would or would not either marry or employ the individuals described "all other things being equal." Following each BI scale was a nine-point scale for the SS to report how confident they felt about the decision just made. The data for only five stimuli configurations are reported in this paper. These five stimuli types were: $\mathrm{HHM}+\mathrm{M}-, \mathrm{HM}+\mathrm{M}+\mathrm{M}-$, $\mathrm{M}+\mathrm{M}+\mathrm{M}-\mathrm{M}-, \mathrm{LM}-\mathrm{M}+\mathrm{M}-$, and $\mathrm{LLM}+\mathrm{M}-$. The Ss responded to 16 other stimuli which can be treated as buffer stimuli. The Ss were fulfilling an introductory psychology course requirement by participating. Employ BIs were reported by $82 \mathrm{Ss}$ and the marry BIs were reported by 44 Ss. There are seldom sex differences in such judgments, and Posavac and McKillip (1972) found none.

\section{RESULTS AND DISCUSSION}

The mean BIs are reported in Table 1. The comparisons which test the first hypothesis are between the differences from the neutral stimulus of the positive and negative stimuli. Since there were two levels of polarization for both marry and employ BIs, there are four tests of the hypothesis that descriptions made up primarily of $\mathrm{L}$ and $\mathrm{M}$ traits would result in more polarized BIs than would descriptions made up primarily of $\mathrm{H}$ and $\mathrm{M}+$ traits. Three of these tests were highly significant $(\mathrm{ps}<.005)$, and the fourth (favorable, low polarization for marry BIs) is in the correct direction although not significant.

The second hypothesis was not supported. Negative triats were not consistently weighted more heavily for marry BIs than for employ BIs. The hypothesis appeared to receive some support for the moderately polarized descriptions but not for the highly polarized stimuli. Some differences which were not expected were noted

Table 2

Mean Estimates of Confidence in the Ratings of the Trait Combinations

\begin{tabular}{lccccccc}
\hline \multirow{2}{*}{$\begin{array}{c}\text { Behavioral } \\
\text { Intention }\end{array}$} & \multicolumn{2}{c}{ Favorable } & & \multirow{2}{*}{ Neutral } & & \multicolumn{2}{c}{ Unfavorable } \\
\cline { 2 - 3 } Dimension & HP & LP & & & LP & HP \\
\hline Employ & 6.95 & 6.23 & & 5.85 & & 6.20 & 6.84 \\
Marry & 6.61 & 6.43 & & 5.93 & & 7.14 & 7.02 \\
\hline
\end{tabular}

Note-HP $=$ high polarization, $L P=$ low polarization. 
when the marry and employ BIs were compared for the positive descriptions. Ss reported lower marry BIs compared to employ BIs when evaluating positive stimuli $(\mathrm{t}=2.07, \mathrm{df}=124, \mathrm{p}<.05$ and $\mathrm{t}=2.28, \mathrm{df}=$ $124, \mathrm{p}<.05$ for the moderately and highly polarized stimuli, respectively). The mean marry BI for LM- of 2.52 does not follow the overall pattern in the table.

Mean confidence judgments are contained in Table 2. As in Posavac and McKillip (1972), confidence increased as the mean judgment of the description departed from the midpoint of the scale. The four differences between confidence in the judgments of the highly polarized stimuli and the neutral stimulus were quite significant (ps $<.001$ ). Three of the four differences between moderately polarized stimuli and the neutral stimulus were significant $(\mathrm{ps}<.05)$. The remaining difference was in the correct direction but was not significant. Among the employ BI judgments, the Ss were more confident of their judgments of the highly polarized stimuli relative to the moderately polarized stimuli $(\mathrm{t}=2.59, \mathrm{df}=81$, $\mathrm{p}<.01$ and $\mathrm{t}=2.17, \mathrm{df}=81, \mathrm{p}<.05)$ for the positive and the negative descriptions, respectively). These differences were not significant for marry BI judgments. Thus, Hypothesis 3 was supported for employ BI. Hypothesis 4, which suggested that negative traits would be weighted more heavily than positive traits in judgments of confidence as in BIs, was not supported.

\section{GENERAL DISCUSSION}

The present study widens the applicability of information integration principles as urged by Rosenberg and Olshan (1971). The finding that negative information leads to more extreme negative BI reports than equally polarized positive information, supports the earlier work of Hamilton and Huffman (1971) using semantic differential judgments. Both sets of results are congruent with the finding that negative information is more useful in making attributions of the motives and personalities of others (Kanouse \& Hanson, 1972). However, the Ss' confidence in their reports of BIs was not differentially influenced by positive and negative information.

When these data are taken together with Posavac and McKillip's results, it is necessary to reconsider the meaning of "information" as used in these studies. In the earlier paper, the hypothesis that confidence would increase as amount of information in the descriptions increased was supported. "Amount of information" was defined as number of traits in the description. Essentially, the same hypothesis was tested in the present study with negative traits hypothesized to convey more information than positive traits. The failure to support this hypothesis and the pattern of the data in Posavac and McKillip (1972) strongly suggest that although negative traits are weighted more heavily than positive traits they do not lead to greater subjective confidence in a way that is parallel to the influence of greater set sizes. Longer descriptions evoke more extreme reports of BIs and greater confidence than shorter descriptions. Negative descriptions evoke more extreme reports of BIs than positive descriptions but do not evoke greater confidence reports. Further research is required to explore why increasing one kind of information leads to more confidence but another kind does not. One possibility is that confidence may increase only when Ss preceive differing amounts of content in the descriptions. Perhaps Ss use a rule related to the conception of standard error which decreases as sample size increases. A larger sample of traits (more content) elicits more confidence than a smaller sample. This view is compatible with Sloan and Ostrom's (1974) finding that confidence was not effected by set size in a between $\mathrm{S}$ design. Such a design of course, does not permit the Ss to perceive nor to respond to differing amounts of content.

\section{REFERENCES}

Anderson, N. H. Averaging model analysis of set-size effect in impression formation. Journal of Experimental Psychology, $1967,75,158-165$.

Hamilton, D. L., \& Huffman, L. J. Generality of impression formation processes for evaluative and nonevaluative judgments. Journal of Personality \& Social Psychology, 1971, 20, 200-207.

Kanouse, D. E., \& Hanson, L. R., Jr. Negativity in evaluations. In E. E. Jones, D. E. Kanouse, H. H. Kelley, R. E. Nisbett, S Valins \& B. Winer (Eds.). Attribution: Perceiving the causes of behavior. Morristown, N. J: General Learning Press, 1972.

Posavac, E. J., \& McKillip, J. The set size effect and confidence in reports of behavioral intentions. Psychonomic Science, 1972, 19, 94-96.

Rosenberg, S. \& Olshan, K. Evaluative and descriptive aspects of personality perception. Journal of Personality \& Social Psychology, 1970, 16, 619-626.

Sloan, L. R., \& Ostrom T. M. Amount of information and interpersonal judgment. Journal of Personality \& Social Psychology, 1974, 19, 23-29.

(Received for publication August 3, 1974.) 